\title{
Korelasi, Motivasi, dan Prospek terhadap Hasil Belajar Bahasa Indonesia Mahasiswa Amerika di Program BIPA
}

\author{
Mohammad Hudha Nursyairofi ${ }^{1}$, Rizman Usman ${ }^{2}$, Gatut Susanto ${ }^{3}$ \\ ${ }^{1}$ Keguruan Bahasa-Universitas Negeri Malang \\ ${ }^{2}$ Pendidikan Bahasa Jerman-Universitas Negeri Malang \\ ${ }^{3}$ Pendidikan Bahasa Indonesia-Universitas Negeri Malang
}

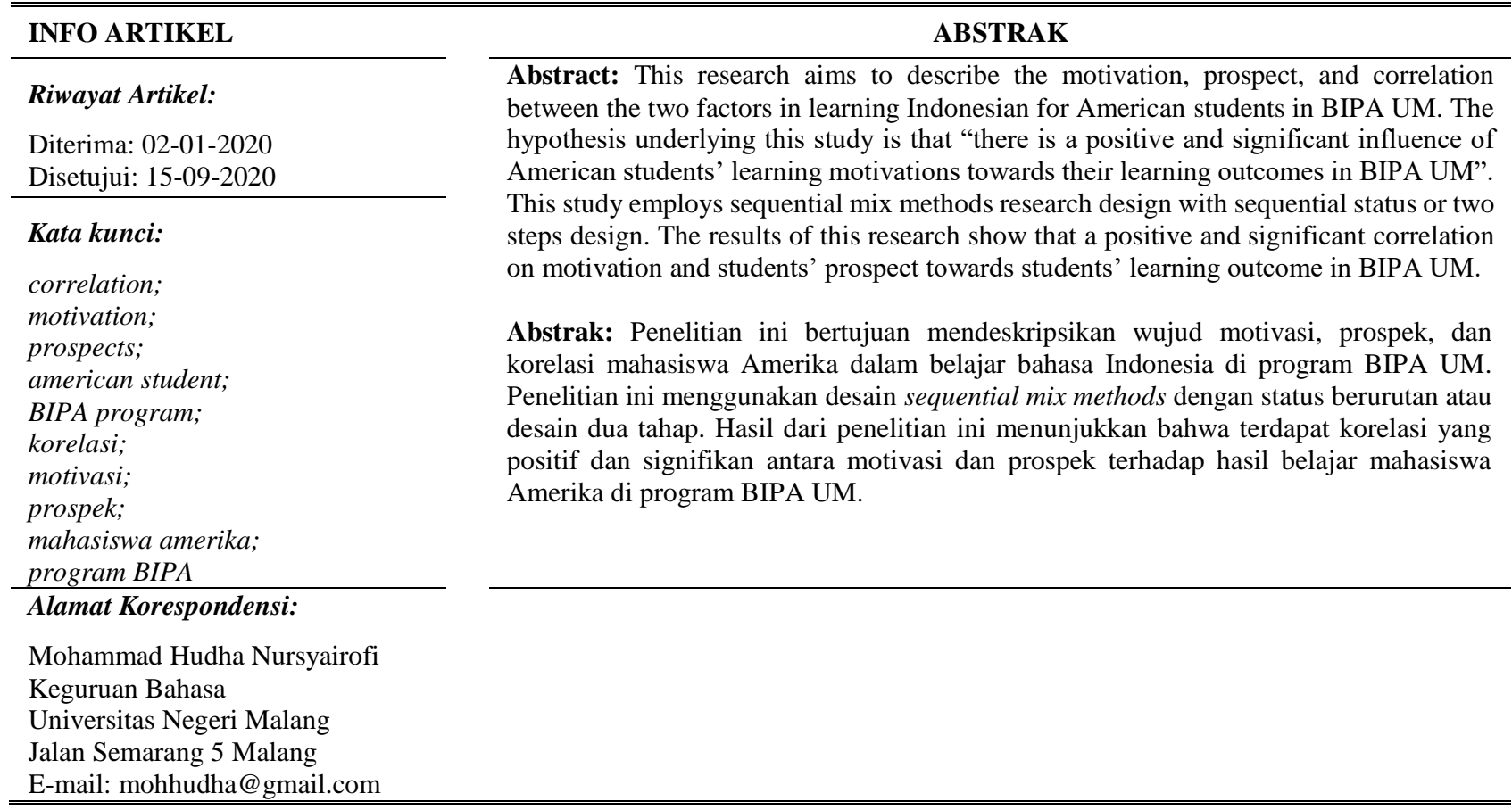

Bahasa Indonesia bagi Penutur Asing (BIPA) merupakan program pembelajaran bahasa Indonesia yang dikhususkan bagi penutur asing. Pembelajaran bahasa Indonesia bagi penutur asing ini tidak hanya dilaksanakan di dalam negeri, tetapi juga di luar negeri. Di dalam negeri sendiri, program BIPA telah diselenggarakan di perguruan tinggi negeri dan swasta. Program BIPA di Indonesia salah satunya dilaksanakan di Universitas Negeri Malang yang telah menyelenggarakan pembelajaran BIPA sejak lama dan terbukti sudah ada kurang lebih 10 negara yang bekerja sama dengan Universitas Negeri Malang. Salah satu negara yang bekerja sama dengan Universitas Negeri Malang adalah Amerika Serikat melalui programnya Critical Language Schoolarship (CLS). Program CLS adalah program beasiswa bahasa pemerintah Amerika untuk mahasiswanya Amerika yang sudah berjalan selama sembilan tahun. Program ini adalah program pembelajaran BIPA yang eksklusif karena memiliki target kemampuan komunikasi lisan mahasiswanya dalam waktu singkat, yaitu dua bulan. Pada kegiatan pembelajaran di dalam maupun luar kelas, mahasiswa diharuskan untuk selalu menggunakan bahasa Indonesia sehingga pemerolehan bahasa mahasiswa akan lebih maksimal. Program ini pernah dinilai sukses diselenggarakan oleh BIPA UM pada tahun 2011 (Azizah, Widodo, dan Lestari, 2015).

Selama pelaksanaan program, banyak hal yang memengaruhi kesuksesan proses pembelajaran. Permasalahanpermasalahan yang muncul dalam pembelajaran di program CLS cukup banyak. Permasalahan ini muncul karena banyak faktor dan salah satunya adalah motivasi mahasiswa. Motivasi belajar mahasiswa ini dipengaruhi oleh dua aspek, yaitu internal dan eksternal. Aspek internal dapat diartikan sebagai keyakinan mahasiswa dalam belajar bahasa Indonesia, aspek afektif seperti rasa ingin mengatahui bahasa Indonesia, dan faktor-faktor umum yang terkait dengan umur dan kepribadian. Sementara aspek eksternal berkaitan dengan bahasa Indonesia, budaya Indonesia, komponen pembelajaran di program CLS, tempat pembelajaran, dan orientasi pihak pelaksanaan program baik penyelenggara di Amerika maupun di Indonesia dalam hal ini BIPA UM. Azizah, Widodo, dan Lestari (2015) menyatakan bahwa mahasiswa program CLS mengalami problematika non kebahasaan antara lain; (1) benturan budaya dalam penyesuaian pebelajar dengan kelas, guru, dan tutor, (2) pemasangan tutor yang tidak tepat karena karakter pebelajar yang kontras dengan tutor, (3) kondisi lingkungan rumah tinggal yang tak mendukung terjadinya komunikasi bahasa Indonesia karena penghuni selalu mengajak berbahasa Inggris, dan (4) kondisi psikologis pebelajar yang fluktuatif akibat persaingan, stres dengan tugas, capai, dan rindu keluarga. Hal ini tentu membutuhkan solusi agar motivasi belajar mahasiswa 
dapat ditingkatkan. Oleh karena itu, perlu dicari tahu apa saja wujud motivasi belajar mahasiswa Amerika di program BIPA UM untuk kemudian diklasifikasikan berdasarkan kebutuhan solutif terhadap target keberhasilan belajar mahasiswa.

Chaer (2009) menyatakan bahwa orang yang di dalam dirinya terdapat motivasi, dorongan, tujuan dan keinginan kuat, terhadap hal yang ingin dicapainya cenderung akan lebih berhasil dibandingkan orang yang kurang memiliki motivasi, dorongan, tujuan dan keinginan. Maka dari itu, dalam upaya meningkatkan kualitas pembelajaran berbagai upaya harus dilakukan yaitu dengan meningkatkan motivasi belajar mahasiswa. Selain itu, motivasi belajar juga dipengaruhi cita-cita atau aspirasi mahasiswa. Dalam proses pembelajaran selalu diharapkan mahasiswa untuk memiliki motivasi yang tinggi sehingga dapat mencapai apa yang menjadi tujuan dalam belajar. Oleh karena itu, motivasi perlu diperkuat dengan tujuan agar mahasiswa memiliki motivasi yang tinggi sehingga dapat mencapai hasil belajar yang maksimal. Sulaeman (2019) menyatakan bahwa motivasi belajar mempunyai pengaruh yang signifikan terhadap hasil pembelajaran bahasa Indonesia mahasiswa program BIPA.

Faktor motivasi menjadi faktor penting guna menunjang peningkatan hasil belajar karena motivasi belajar yang rendah akan memengaruhi proses belajar dan kemauan untuk sukses atau berhasil mencapai tujuan belajar. Sebaliknya, apabila mahasiswa bermotivasi tinggi mereka akan mempunyai kemauan dan keaktifan yang baik saat kegiatan pembelajaran. Menurut Maunah (2014) seseorang akan termotivasi atau terdorong untuk berusaha menganalisis sesuatu dengan sebaik-baiknya jika mengetahui pentingnya hasil belajar. Memiliki motivasi belajar tinggi akan memaksimalkan prestasi belajar (Sardiman, 2004). Penelitian yang dilakukan oleh Jamal, (2017) menjelaskan semakin tinggi motivasi belajar seseorang akan semakin tinggi juga prestasinya. Didukung penelitian Novalinda, Kantun, \& Widodo (2017) bahwa motivasi mempunyai dampak signifikan pada output kegiatan belajar mengajar. Keterkaitan motivasi dengan prestasi belajar tersebut dikarenakan motivasi dipengaruhi oleh motivasi, faktor-faktor dalam belajar, keinginan, keadaan, keadaan lingkungan, cita-cita dan upaya yang dilakukan guru dalam memahirkan pemelajar (Dimyati \& Mudjiono, 2010). Indikator dalam motivasi belajar adalah sebagai berikut: (1) penghargaan dalam belajar, (2) harapan dan cita-cita masa depan, (3) dorongan dan kebutuhan dalam belajar, (4) hasrat dan keinginan berhasil, (5) lingkungan belajar yang kondusif, (6) kegiatan yang menarik dalam belajar (Uno, 2008). Slameto (2010) menjelaskan bahwa seseorang berhasil atau tidak dalam belajar disebabkan oleh beberapa factor. Faktor-faktor ini adalah internal (berasal dari dalam peserta didik) seperti faktor jasmaniah dan psikologis, dan eksternal (berasal dari luar peserta didik) seperti faktor keluarga, sekolah, dan masyarakat. Oleh sebab itu, motivasi memiliki faktor penting pada keberhasilan proses pembelajaran. Hal ini juga menjadi dasar pemahaman yang sama bahwa ketika mahasiswa asing yang belajar bahasa Indonesia memiliki motivasi yang besar akan menerima hasil pencapaian yang besar pula. Weiner (dalam Soemanto, 2003) yang menyatakan bahwa apabila mahasiswa memiliki motivasi akan berhasil Dia akan bekerja lebih keras daripada mahasiswa yang memiliki motivasi untuk berhasil. Mahasiswa yang ingin berhasil akan terus memacu dirinya mengerjakan segala pekerjaan yang diberikan kepadanya. Oleh karena itu, perlu diukur terlebih dahulu seberapa besar motivasi mahasiswa dalam belajar bahas Indonesia di BIPA UM untuk mengetahui korelasinya terhadap hasil belajar.

Sudjana (2009) menyatakan bahwa hasil belajar adalah perubahan tingkah laku untuk mencapai hasil belajar yang mencakup bidang afektif, psikomotorik dan kognitif. Sedangkan Dimyati dan Mudjiono (2010) menyatakan bahwa hasil belajar adalah hasil dari interaksi tindak mengajar dan tindak belajar. Ataupun dapat diartikan sebagai proses untuk melihat penguasaan pembelajaran mahasiswa setelah mengikuti proses belajar mengajar, sesuai dengan tujuan yang telah ditetapkan. Agustina, Andayani \& Wardani (2013) menyatakan bahawa penilaian pembelajaran BIPA adalah proses untuk melihat kesesuaian keberhasilan antara proses dan hasil dari pembelajaran bahasa. Pengelompokan atau taksonomi yang sering digunakan dalam menggambarkan peningkatan keterampilan kognitif siswa yang memulai dari level pemula ke level tertinggi adalah taksonomi Bloom. Taksonomi Bloom kemudian dikembangkan oleh Anderson \& Krathwohl menjadi beberapa kategori yaitu mengingat, memahami, mengaplikasikan, menganalisis, mengevaluasi, dan mencipta Anderson \& Krathwohl (2015). Tinggi rendahnya hasil belajar mahasiswa dipengaruhi banyak faktor, baik yang bersifat internal maupun eksternal. Faktor-faktor tersebut sangat memengaruhi upaya mahasiswa dalam mencapai hasil belajar dan dapat mendukung tercapainya tujuan pembelajaran yang diharapkan. Dari beberapa teori di atas, maka hasil belajar yang dimaksud dalam penelitian ini adalah nilai akhir atau rata-rata dari nilai kuis, ujian tengah semester dan ujian akhir semester.

Menurut Hamalik (2008) tujuan belajar dibagi menjadi tiga komponen yaitu tingkah laku mahasiswa setelah belajar, kondisi tes atau situasi ketika mahasiswa dituntut untuk menunjukkan tingkah laku dan kuran perilaku yang digunakan untuk membuat penilaian akhir dari perilaku mahasiswa tersebut. Saud (2010) mengemukakan bahwa tujuan atau prospek belajar dapat dibagi menjadi lima jenis yaitu: (1) mengadakan perubahan di dalam diri atau mengubah tingkah laku (2) mengubah kebiasaan buruk menjadi baik, (3) mengubah sikap negatif menjadi positif, tidak hormat menjadi hormat, benci menjadi sayang, dan sebagainya, (4) meningkatkan kecakapan atau keterampilan, dan (5) menambah pengetahuan berbagai bidang ilmu. Tujuan belajar selalu dihubungkan dengan manfaat dan fungsi dari belajar. Seorang mahasiswa juga dapat belajar dengan baik jika memiliki prospek dalam belajarnya, seperti memiliki keinginan untuk mengubah sikapnya menjadi lebih baik ketika mengikuti pembelajaran, mulai meninggalkan kebiasaan-kebiasaan buruk menjadi lebih baik, dan memiliki peningkatan keterampilan di berbagai bidang. Oleh karena itu, perlu dicari tahu apa saja wujud tujuan/prospek belajar mahasiswa Amerika program BIPA UM untuk dapat mengukur korelasinya terhadap motivasi dan hasil belajar. 
Berdasarkan latar belakang di atas, fokus penelitian ini adalah mengenai wujud motivasi dan prospek belajar serta korelasinya terhadap hasil belajar mahasiswa Amerika di program BIPA UM. Penelitian ini menjadi penting untuk dilakukan karena belum ada penelitian yang berfokus pada subjek BIPA dengan fokus pada variabel motivasi dan prospek belajar. Gambaran kerangka berpikir dalam penelitian ini ditunjukkan pada gambar 1.

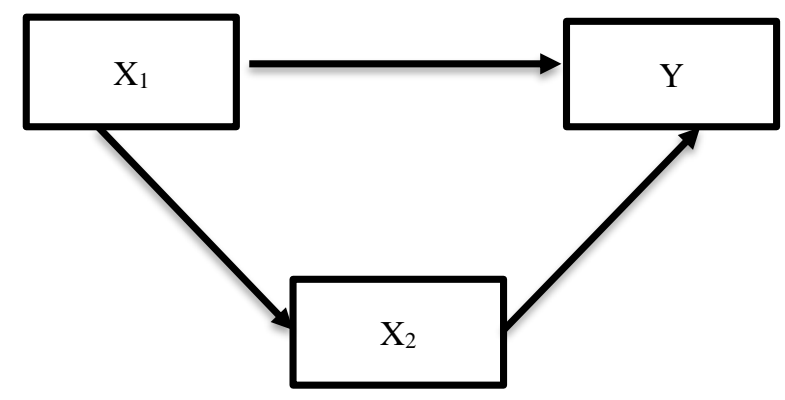

Gambar 1. Kerangka Berpikir Tuckman (dalam Sugiyono, 2009)

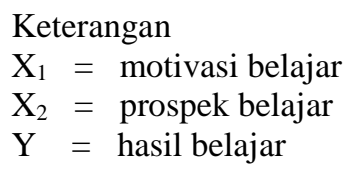

\section{METODE}

Penelitian ini menggunakan desain penelitian sequential mix methods dengan status berurutan atau desain dua tahap. Peneliti menggunakan metode kuantitatif terlebih dahulu untuk menguji hipotesis dan mencari korelasi motivasi dan hasil belajar mahasiswa Amerika di program BIPA UM, kemudian menggunakan metode kualitatif untuk menemukan wujud motivasi dan prospek belajar bahasa Indonesia mahasiswa Amerika di program BIPA UM. Selanjutnya menggunakan metode kualitatif untuk menemukan korelasi motivasi dan prospek mahasiswa Amerika terhadap hasil belajar bahasa Indonesia di program BIPA UM. Instrumen penelitian ini adalah observasi, wawancara, dan angket. Observasi dilakukan dengan cara mengamati perkembangan motivasi mahasiswa Amerika yang bersumber pada jurnal harian mahasiswa dan jurnal mengajar guru. Observasi dilakukan untuk menemukan wujud motivasi belajar sedangkan wawancara dilakukan untuk mengetahui prospek mahasiswa Amerika belajar bahasa Indonesia di BIPA UM. Pedoman wawancara berupa pertanyaan-pertanyaan yang ditujukan kepada mahasiswa tentang tantangan dan prospek/tujuan belajar mahasiswa. Angket digunakan untuk mengukur tingkat motivasi belajar mahasiswa Amerika di BIPA UM. Angket terdiri dari 30 pertanyaan tentang motivasi internal dan eksternal belajar bahasa Indonesia.

Analisis data kuantitatif dalam penelitian ini menggunakan bantuan program SPSS 25. Analisis data yang dilakukan menggunakan SPSS 25 antara lain (1) uji validitas data menggunakan bivariate correlations, (2) uji reliabiltas data menggunakan reliability analysis, (3) uji linieritas data menggunakan compare means, (4) frekuensi statistik motivasi dan hasil belajar menggunakan frequencies descriptive statistics, dan (5) korelasi motivasi terhadap hasil belajar menggunakan bivariate correlations. Analisis data kuantiatif dijadikan sebagai metode utama sedangkan analisis data kualitatif menjelaskan lebih dalam dan terperinci tentang data kuantitatif.

\section{HASIL}

Data variabel motivasi belajar diperoleh melalui kuesioner yang tediri dari 30 pertanyaan dengan jumlah responden 12 mahasiswa. Terdapat empat alternatif jawaban dengan skor tertinggi adalah 4 dan terendah adalah 1 . Berikut ini adalah hasil perhitungan statistik dan frekuensi menggunakan program SPSS 25 (Tabel 1).

Tabel 1. Hasil Perhitungan Frekuensi Statistik Motivasi Belajar Mahasiswa Amerika di BIPA UM

\begin{tabular}{lll}
\hline \multicolumn{1}{c}{$\mathbf{N}$} & \multicolumn{1}{c}{ Valid } & $\mathbf{1 2}$ \\
\cline { 2 - 3 } & \multicolumn{1}{c}{ Missing } & $\mathbf{0}$ \\
\hline Mean & 67.0142 & \\
Std. Deviation & 10.56168 & \\
Variance & 111.549 & \\
Range & 29.17 & \\
Minimum & 50.83 & \\
Maximum & 80.00 & \\
Sum & 804.17 & \\
\hline
\end{tabular}


Tabel 1. Hasil Perhitungan Frekuensi Statistik Motivasi Belajar Mahasiswa Amerika di BIPA UM (Lanjutan)

\begin{tabular}{|c|c|c|c|c|c|}
\hline & & Frequency & Percent & Valid Percent & Cumulative Percent \\
\hline \multirow{11}{*}{$\stackrel{\overrightarrow{0}}{\stackrel{0}{0}}$} & 50.83 & 1 & 8.3 & 8.3 & 8.3 \\
\hline & 52.50 & 2 & 16.7 & 16.7 & 25.0 \\
\hline & 64.17 & 1 & 8.3 & 8.3 & 33.3 \\
\hline & 65.00 & 1 & 8.3 & 8.3 & 41.7 \\
\hline & 66.67 & 2 & 16.7 & 16.7 & 58.3 \\
\hline & 75.00 & 1 & 8.3 & 8.3 & 66.7 \\
\hline & 75.83 & 1 & 8.3 & 8.3 & 75.0 \\
\hline & 76.67 & 1 & 8.3 & 8.3 & 83.3 \\
\hline & 78.33 & 1 & 8.3 & 8.3 & 91.7 \\
\hline & 80.00 & 1 & 8.3 & 8.3 & 100.0 \\
\hline & Total & 12 & 100.0 & 100.0 & \\
\hline
\end{tabular}

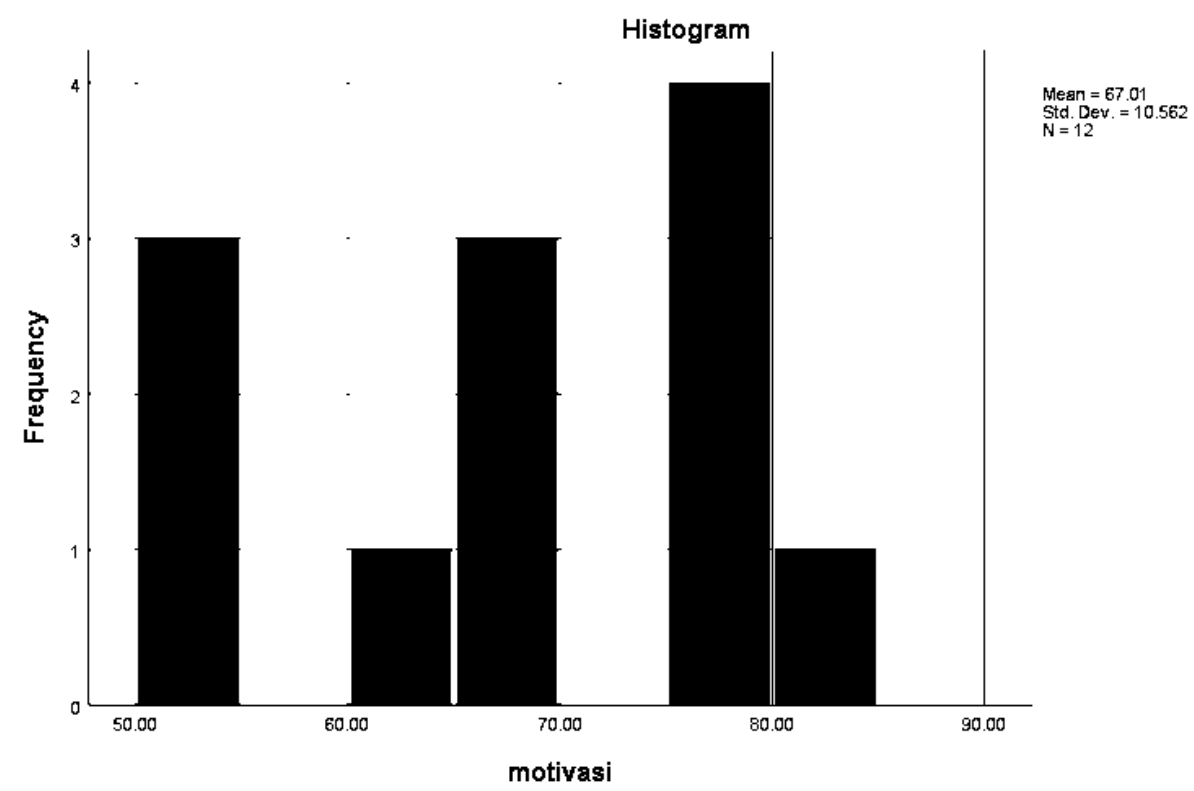

\section{Gambar 2. Hasil Perhitungan Frekuensi Statistik Motivasi Belajar Mahasiswa Amerika di BIPA UM}

Berdasarkan hasil perhitungan pada tabel 1 dapat disimpulkan bahwa skor tertinggi 80,00 dan skor terendah 50,83 . Berdasarkan skor tersebut dapat ditentukan rentang data sebesar $80-50,83=29,17$. Penentuan jumlah interval menggunakan rumus (interval $=1+3,30 \log \mathrm{n}$ ) dengan pengertian $\mathrm{n}$ adalah jumlah responden yaitu 12 . Jadi interval $=1+3,30 \log 12(1,079)$ hasilnya adalah 4,56 (dibulatkan menjadi 5, sedangkan untuk panjang rentang adalah 29,17/ 5= 5,83. Berikut ini adalah tabel dan grafik distribusi prosentase dan kategori motivasi belajar bahasa Indonesia:

Tabel 2. Persentase dan Kategori Motivasi Belajar Mahasiswa Amerika di BIPA UM

\begin{tabular}{cccll}
\hline No & Interval & F & $\%$ & Kategori \\
\hline 1 & $74,18-80,01$ & 5 & 41,67 & Sangat Tinggi \\
2 & $68,34-74,17$ & - & & Tinggi \\
3 & $62,51-68,33$ & 4 & $33,33 \%$ & Sedang \\
4 & $56,67-62,50$ & - & - & Rendah \\
5 & $50,83-56,66$ & 3 & $25 \%$ & Sangat Rendah \\
\hline
\end{tabular}




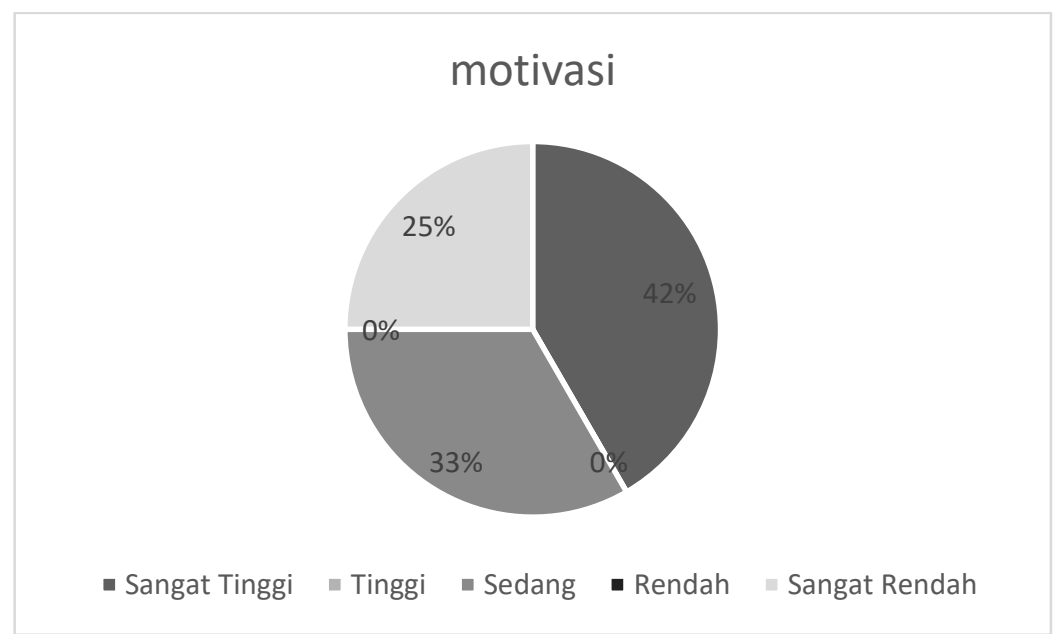

\section{Gambar 3. Persentase dan Kategori Motivasi Belajar Mahasiswa Amerika di BIPA UM}

Berdasarkan hasil perhitungan pada gambar 3 dapat disimpulkan bahwa frekuensi motivasi belajar kategori sangat tinggi sebanyak lima mahasiswa (41,67\%), frekuensi kategori sedang sebanyak empat mahasiswa (33,33\%), dan frekuensi kategori sangat rendah sebanyak tiga mahasiswa (25\%). Data variabel hasil belajar diperoleh melalui rata-rata nilai kuis dan ujian akhir mahasiswa yang berjumlah 12 mahasiswa. Berikut ini adalah hasil perhitungan statistik dan frekuensi menggunakan program SPSS 25.

Tabel 3. Hasil Perhitungan Frekuensi Statistik Hasil Belajar Mahasiswa Amerika di BIPA UM

\begin{tabular}{lll}
\hline $\mathbf{N}$ & Valid & 12 \\
\cline { 2 - 3 } & Missing & 0 \\
\hline Mean & 94.6592 \\
Median & 94.8600 \\
Std. Deviation & 1.23933 \\
Variance & 1.536 \\
Range & 4.23 \\
Minimum & 92.76 \\
Maximum & 96.99 \\
Sum & 1135.91 \\
\hline
\end{tabular}

\begin{tabular}{|c|c|c|c|c|c|}
\hline & & Frequency & Percent & Valid Percent & Cumulative Percent \\
\hline \multirow[t]{2}{*}{ 递 } & $\begin{array}{l}92.76 \\
93.17 \\
93.37 \\
94.00 \\
94.35 \\
94.80 \\
94.92 \\
94.95 \\
95.08 \\
95.18 \\
96.34 \\
96.99\end{array}$ & $\begin{array}{l}1 \\
1 \\
1 \\
1 \\
1 \\
1 \\
1 \\
1 \\
1 \\
1 \\
1 \\
1\end{array}$ & $\begin{array}{l}8.3 \\
8.3 \\
8.3 \\
8.3 \\
8.3 \\
8.3 \\
8.3 \\
8.3 \\
8.3 \\
8.3 \\
8.3 \\
8.3\end{array}$ & $\begin{array}{l}8.3 \\
8.3 \\
8.3 \\
8.3 \\
8.3 \\
8.3 \\
8.3 \\
8.3 \\
8.3 \\
8.3 \\
8.3 \\
8.3\end{array}$ & $\begin{array}{c}8.3 \\
16.7 \\
25.0 \\
33.3 \\
41.7 \\
50.0 \\
58.3 \\
66.7 \\
75.0 \\
83.3 \\
91.7 \\
100.0\end{array}$ \\
\hline & Total & 12 & 100.0 & 100.0 & \\
\hline
\end{tabular}




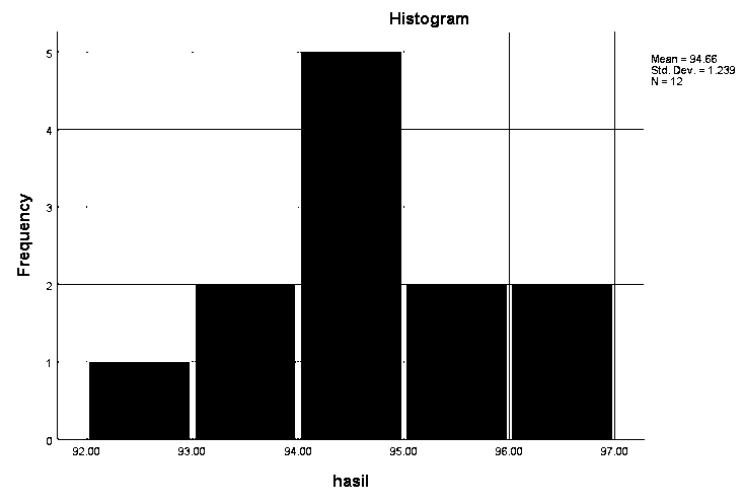

\section{Gambar 3. Hasil Perhitungan Frekuensi Statistik Hasil Belajar Mahasiswa Amerika di BIPA UM}

Berdasarkan hasil perhitungan di atas diketahui bahwa skor tertinggi adalah 96,99 dan skor terendah adalah 92.76 . Berdasarkan skor tersebut dapat ditentukan rentang data sebesar 96,99-92,76 =4,23. Penentuan jumlah interval menggunakan rumus (interval $=1+3,30 \log n$ ) dengan pengertian $n$ adalah jumlah responden yaitu 12 . Jadi interval $=1+3,30 \log 12(1.079)$ hasilnya adalah 4,56 dibulatkan menjadi 5 , sedangkan untuk panjang rentang adalah 4,23/5=0,85. Berikut ini adalah tabel dan grafik distribusi prosentase dan kategori hasil belajar bahasa Indonesia:

Tabel 4. Persentase dan Kategori Hasil Belajar Mahasiswa Amerika di BIPA UM

\begin{tabular}{cllll}
\hline No & Interval & $\mathbf{F}$ & $\mathbf{\%}$ & Kategori \\
\hline 1 & $96,20-97,05$ & 2 & $16,67 \%$ & Sangat Tinggi \\
2 & $95,34-96,19$ & - & - & Tinggi \\
3 & $94,48-95,33$ & 5 & $41,67 \%$ & Sedang \\
4 & $93,62-94,47$ & 2 & $16,67 \%$ & Rendah \\
5 & $92,76-93,61$ & 3 & $25 \%$ & Sangat Rendah \\
\hline
\end{tabular}

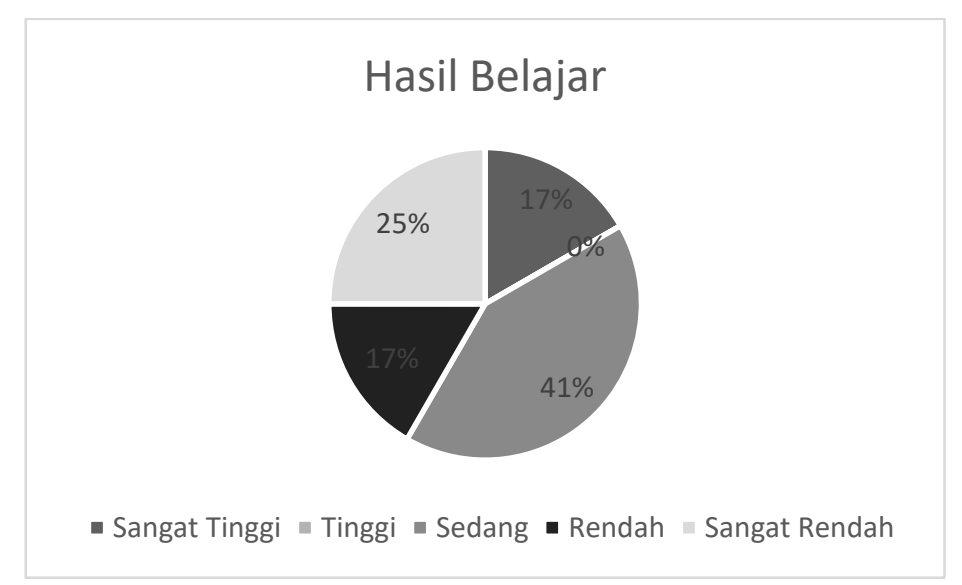

Gambar 4. Persentase dan Kategori Hasil Belajar Mahasiswa Amerika di BIPA UM

Berdasarkan hasil perhitungan di atas di atas dapat disimpulkan bahwa frekuensi motivasi belajar kategori sangat tinggi sebanyak dua mahasiswa $(16,67 \%)$, frekuensi kategori sedang sebanyak lima mahasiswa $(41,67 \%)$, frekuensi kategori sangat rendah sebanyak dua mahasiswa $(16,67 \%)$, dan frekuensi kategori sangat rendah sebanyak tiga mahasiswa $(25 \%)$.

\section{PEMBAHASAN}

Wujud Motivasi Belajar Mahasiswa Amerika di BIPA UM

Berikut ini adalah temuan-temuan dari penelitian mengenai wujud motivasi bealajar mahasiswa yang tercermin dalam kutipan-kutipan jurnal belajar mahasiswa Amerika di CLS selama dua bulan. 


\section{Tabel 5. Wujud Motivasi Internal Dalam Kutipan-Kutipan Jurnal Mahasiswa Amerika di BIPA UM}

\begin{tabular}{|c|c|c|c|}
\hline No & Faktor Motivasi Internal & & Kutipan \\
\hline \multirow[t]{3}{*}{1} & $\begin{array}{l}\text { Ketertarikan intrinsik pada } \\
\text { kegiatan }\end{array}$ & 1) & $\begin{array}{l}\text { Saya pergi ke kelas tari hari ini. Saya suka sekali karena saya suka music dan tari. Kelas sulit } \\
\text { tapi saya belajar banyak. }\end{array}$ \\
\hline & & 2) & $\begin{array}{l}\text { Hari ini kami pergi ke wonosari untuk belajar teh. Kami naik bus dan pergi dua jam ke } \\
\text { wonosari, kota di gunung. }\end{array}$ \\
\hline & & 3) & Setelah ekskursi itu saya capai dan kaki saya sakit karena ekskursi itu butuh banyak perjalanan. \\
\hline \multirow[t]{2}{*}{2} & $\begin{array}{l}\text { Nilai yang dirasakan dalam } \\
\text { kegiatan }\end{array}$ & 1) & $\begin{array}{l}\text { Hari ini tanggal } 4 \text { juli atau hari kemerdekaan Amerika. Guru guru dan staff CLS membuat } \\
\text { pesta untuk semua mahasiswa dan tutor CLS dengan banyak lomba dan permainan. saya sakit } \\
\text { dan pusing jadi saya pulang awal. }\end{array}$ \\
\hline & & 2) & $\begin{array}{l}\text { Hari ini saya belajar dengan permainan baru, permainan pertama adalah bekel. Permaianan } \\
\text { kedua adalah balus. }\end{array}$ \\
\hline \multirow[t]{2}{*}{3} & Rasa pengendalian & 1) & $\begin{array}{l}\text { Hari ini saya sedikit kurang sehat di kelas saya. Saya masih sakit sedikit. Walaupun suara saya } \\
\text { sudah hamper sepenuhnya kembali. }\end{array}$ \\
\hline & & 2) & Hari ini senang sekali! Tapi tadi pagi ada kuis yang sedikit sulit. \\
\hline \multirow[t]{2}{*}{4} & Penguasaan & 1) & $\begin{array}{l}\text { Setelah itu, kami belajar tentang idiom dalam bahasa Indonesia. Toipik ini menarik sekali } \\
\text { karena idiom adalah kata-kata yang tidak bisa diterjemahkan dalam bahasa bahasa lain. Untuk } \\
\text { menggunakan idiom seharusnya Anda mengerti bahasa Indonesia. }\end{array}$ \\
\hline & & 2) & $\begin{array}{l}\text { Hari ini di kelas semua mahasiswa membagi informasi tentang music tradisional. Mbak sarina } \\
\text { dan saya menjelaskan alat music gamelan tapi mahasiswa lain membagi musik tradisional dari } \\
\text { Amerika. Nanti guru-guru menunjukkan alat music namanya sasando krpada kami. Alatnya } \\
\text { musiknya mempunyai suara yang bagus. }\end{array}$ \\
\hline \multirow[t]{3}{*}{5} & Konsep diri & 1) & Sangat membosankan kalau tidak bisa menyuarakan pikiran dan perasaan saya. \\
\hline & & 2) & $\begin{array}{l}\text { Wah hari ini sangat susah. Kami pergi ke kelas yang pertama. Selama kelas kami menjawab } \\
\text { pertanyaan. Kegiatan ini memang susah karena saya sering tidak mengerti pertanyaannya. }\end{array}$ \\
\hline & & 3) & Saya merasa bahwa pendidikan merupakan salah satu hal yang penting untuk warga papua. \\
\hline \multirow[t]{6}{*}{6} & Sikap & 1) & $\begin{array}{l}\text { Hari ini membuat frustasi karena semua siswa memahami kecuali saya. Topik terlihat } \\
\text { gampang, tetapi saya frustasi karena tidak memahami. }\end{array}$ \\
\hline & & 2) & $\begin{array}{l}\text { Ketika saya bangun, saya masih sakit perut. Meskipun saya sangat suka kelas Rambutan saya } \\
\text { tahu bahwa saya harus istirahat hari ini agar cepat sembuh. }\end{array}$ \\
\hline & & 3) & $\begin{array}{l}\text { Hari ini saya sangat capai sekali, karena itu saya pikir tentang waktu says seharusnya saya } \\
\text { tidur. Walaupun saya biasanya pergi ke kelas Muay Thai setiap kamis, saya mulai percaya } \\
\text { bahwa tidur yang paling penting dibandingkan semuanya. }\end{array}$ \\
\hline & & 4) & Hari ini membuat Frustasi karena siswa memahami kecuali saya. \\
\hline & & 5) & $\begin{array}{l}\text { Hari ini saya merasa sedih. Pagi ini saya menerima berita dari Mbak Rebecca bahwa Pak } \\
\text { Widodo sudah meninggal. }\end{array}$ \\
\hline & & 6) & $\begin{array}{l}\text { Saya menyadari bahwa semua keluarga saya lahir pada hari penting, saya lahir } 28 \text { oktober } \\
\text { adalah hari sumpah pemuda, ibu saya lahir } 11 \text { maret adalah hari dimana bung karno } \\
\text { menandatangani supersemar, dan bapak saya lahir } 19 \text { agustus hamper } 17 \text { agustus hari } \\
\text { kemerdekaan Indonesia seperti kesukaan saya. }\end{array}$ \\
\hline \multirow[t]{3}{*}{7} & Keadaan afektif lain & 1) & $\begin{array}{l}\text { Saya senang karena kemarin saya selesai OPI. Itu tidak sulit. Satu rekomendasi untuk siswa } \\
\text { harus santai. Anda tidak harus rasa gugup. }\end{array}$ \\
\hline & & 2) & Saya gugup tentang kuis. Saya tidak bermain badminton. Saya harap saya siap untuk kuis \\
\hline & & 3) & $\begin{array}{l}\text { Saya sedikit gugup untuk UTS pada hari jumat. Ujiannya terdengar sulit dan saya tidak tahu } \\
\text { bagaimana saya tampil di kelas. Saya selalu merasa seperti saya bicara baik tapi saya tidak } \\
\text { pernah suka nilai dari bagian bicaraan di ujian semangat! }\end{array}$ \\
\hline \multirow[t]{3}{*}{8} & $\begin{array}{l}\text { Perkembangan usia dan jenis } \\
\text { kelamin }\end{array}$ & 1) & $\begin{array}{l}\text { Ketika saya ambil selfi dengan orang-orang tahun lalu di jogja. Lengan atau tangan mereka } \\
\text { tidak dipinggul saya, jika dia laki-laki. Saya pikir mungkin karena di Universitas atau di } \\
\text { Malang itu tidak salah. Sekarang, ketika orang-orang mau ambil foto saya akan berbicara } \\
\text { "tidak boleh". }\end{array}$ \\
\hline & & 2) & Kadang-kadang saya merasa frustasi dengan norma-norma jenis kelasmin di Indonesia. \\
\hline & & 3) & Kadang-kadang saya merasa frustasi dengan norma-norma jenis kelasmin di Indonesia. \\
\hline
\end{tabular}

Dari data penelitian yang sudah dipaparkan di atas sesuai dengan pendapat Ellis (2013), faktor-faktor individu seorang mahasiswa yang belajar bahasa berpengaruh terhadap proses dan mekanisme belajar seseorang. Strategi belajar bahasa akan dipengaruhi oleh faktor perbedaan individu mahasiswa yang secara langsung berpengaruh terhadap hasil belajarnya. 
Tabel 6. Wujud Motivasi Eksternal dalam Kutipan-Kutipan Jurnal Mahasiswa Amerika di BIPA UM

\begin{tabular}{|c|c|c|c|}
\hline No & $\begin{array}{c}\text { Faktor Motivasi } \\
\text { Eksternal }\end{array}$ & & Kutipan \\
\hline \multirow[t]{10}{*}{1} & $\begin{array}{l}\text { Orang yang } \\
\text { berarti/penting }\end{array}$ & 1) & $\begin{array}{l}\text { Saya bertanya kepada Mas Nanang mengapa hukum untuk makanan penting untuk dia } \\
\text { dan perbedaan dari satu dan lainnya. Untuk proyek terakhir saya mau meneliti tentang } \\
\text { hokum makanan di dalam islam. }\end{array}$ \\
\hline & & 2) & $\begin{array}{l}\text { Setiap hari ibu kos memberikan saya dua snack. Hari ini sayur goring dan onde-onde. } \\
\text { Ondeh-ondeh makanan khas cina. }\end{array}$ \\
\hline & & 3) & $\begin{array}{l}\text { Setelah rapat dengan Pak Adam di galeri semeru, saya pulang sendiri. Tetapi sebelum } \\
\text { itu saya membeli kue yang mbak Nissa bawa hari ini. Enak sekali! Saya juga mencoba } \\
\text { yang rasa coklat, tetapi sedikit kering. }\end{array}$ \\
\hline & & 4) & Setelah kelas saya dan tutor duduk di dalam gazebo dan bicara untuk makan malam. \\
\hline & & 5) & $\begin{array}{l}\text { presentasi membuat menu makanan sehat bagus, banyak interaksi dg Mas Wawan sbg } \\
\text { asisten chef. }\end{array}$ \\
\hline & & 6) & $\begin{array}{l}\text { Dia bicara cepat sekali dan saya bingung! Tapi tutor dan Mbak Septa membantu saya } \\
\text { mengerti tentang candi singosari. }\end{array}$ \\
\hline & & 7) & Mas Athif dan Mas Bagus bagus sekali \\
\hline & & 8) & $\begin{array}{l}\text { Saya belajar dengan tutor dan praktik melafalkan kata-kata. Kami belajar dari jam } 6.00 \\
\text { - sampai } 07.00 \text { malam, lalu berbicara gossip panas dan makan snack. }\end{array}$ \\
\hline & & 9) & $\begin{array}{l}\text { Saya belajar bahasa Indonesia dengan tutor. Dia membantu baca buku dan berbicara } \\
\text { bahasa Indonesia. }\end{array}$ \\
\hline & & 10) & Tutor saya tidak berbicara bahasa inggris dan itu membantu juga. \\
\hline \multirow[t]{6}{*}{2} & $\begin{array}{l}\text { Sifat dari interaksi } \\
\text { dengan orang yang } \\
\text { berarti }\end{array}$ & 1) & $\begin{array}{l}\text { Saya berbicara "permisi" ketika saya berjalan melewati dia. Dia menjawab apa-apa yang } \\
\text { tidak saya mengerti. Tetapi saya lebih banyak senang karena saya bisa berbicara bahasa } \\
\text { Indonesia di masyarakat dan mereka tidak lihat bahwa saya seorang bule. }\end{array}$ \\
\hline & & 2) & $\begin{array}{l}\text { Akhir minggu ini sangat menyenangkan tetapi juga sedikit cemas. Kami hanya } \\
\text { berencana tinggal di Bali selama } 2 \text { hari. Dan dua hari sebenarnya tidak cukup untuk } \\
\text { mengalami banyak budaya atau kegiatan di Bali. }\end{array}$ \\
\hline & & 3) & $\begin{array}{l}\text { Hari ini saya akan bertemu murid-murid saya dari SMAN 10. Saya tidak sabar lagi! } \\
\text { Sebenarnya saya sedikit khawatir karena sudah lama saya tidak bertemu dengan mereka, } \\
\text { saya takut saya lupa wajah mereka. }\end{array}$ \\
\hline & & 4) & $\begin{array}{l}\text { Kedua, saya juga belajar tentang budaya di Indonesia. Karena di film itu ada karakter } \\
\text { dengan pacar di internet. Banyak yang pernah punya pacar di internet itu biasa sekali } \\
\text { untuk orang Indonesia. }\end{array}$ \\
\hline & & 5) & $\begin{array}{l}\text { Kami bertemu dengan orang desa, orang senang memasak banyak makanan. Lalu kami } \\
\text { jalan samping sawah. Petani punya ikan koi yang di dalam kolam sawah. Petani punya } \\
\text { banyak tanah itu bagus dengan tanaman sayur. }\end{array}$ \\
\hline & & 6) & $\begin{array}{l}\text { Saya membeli tas kanvas untuk teman saya di Amerika. Saya mencoba menawar dengan } \\
\text { penjual itu, tapi dia tidak mau mengurangi harganya. }\end{array}$ \\
\hline \multirow[t]{5}{*}{3} & Lingkungan belajar & 1) & Saya sangat senang kota-kota baru di Malang. Saya sangat senang ketika tiba di pantai. \\
\hline & & 2) & $\begin{array}{l}\text { Ada kelas ekskursi ke pondok pesantren sangat menarik, karena saya belum tahu banyak } \\
\text { tentang pesantren. Dan saya boleh mencoba baju sopan seperti orang muslim. Jadi saya } \\
\text { memakai jilbab dan baju panjang dan celana longgar dan itu saja sudah menjadi } \\
\text { pengalaman menarik. }\end{array}$ \\
\hline & & 3) & $\begin{array}{l}\text { Hari ini kelas mulai dengan guru-guru meninjau kembali proyek akhir. Mbak Niken } \\
\text { membantu saya dan saya merasa bahwa saya hampir siap! }\end{array}$ \\
\hline & & 4) & $\begin{array}{l}\text { Hari ini untuk kelas kita pergi ke kafe madame wong. Kafe ini sangat keren dan saya } \\
\text { mau kembali lagi ketika saya punya cukup uang. Disana kita belajar bagaimana } \\
\text { memakai idiom Indonesia. Untungnya saya sudah memakai buaya darat. }\end{array}$ \\
\hline & & 5) & $\begin{array}{l}\text { Hari ini sebagai hari yang sempurna. Kami memiliki durian, tamasya kelas, dan banyak } \\
\text { lelucon di mobil. Saya benar-benar berpikir itu keren pergi ke RRI, stasiun radio karena } \\
\text { saya bekerja di stasiun Radio di sekolah saya. }\end{array}$ \\
\hline \multirow[t]{3}{*}{4} & Konteks yang lebih luas & 1) & $\begin{array}{l}\text { Saya dengar berita adalah tiga ledakan di pasuruhan berasal dari Bom. Saya tidak } \\
\text { membayangkan pikiran orang yang dipengaruhi oleh kejadian ini. Saya tinggal lebih } \\
\text { dari } 1.30 \text { menit dari lokasi ledakan dan walaupun } 1 \text { jam lebih jauh. Saya masih merasa } \\
\text { sedikit takut. Apalagi orang yang tinggal lebih dekat daripada saya. }\end{array}$ \\
\hline & & 2) & $\begin{array}{l}\text { Sementara menonton mahasiswa CLS bermain melempar piring, saya bercerita dengan } \\
\text { anak-anak kecil yang juga menonton permainan itu. Walaupun mereka paham apa yang } \\
\text { saya katakan dalam bahasa Indonesia, mereka tidak bisa membalas dalam bahasa } \\
\text { Indonesia, mereka hanya bisa berbicara dalam bahasa daerahnya-bahasa jawa. }\end{array}$ \\
\hline & & 3) & $\begin{array}{l}\text { Di rumah sakit dan di Apotik saya berbicara hampir semuanya berbahasa Indonesia. } \\
\text { Saya hanya berbicara dalam beberapa kata dalam bahasa inggris. }\end{array}$ \\
\hline
\end{tabular}


Dari data penelitian yang di atas sesuai dengan pendapat Williams dan Burden (dalam Matsumoto, 2009) yang telah menyajikan kerangka kerja motivasi L2 terutama berdasarkan masalah yang relevan dengan psikologi pendidikan. Mereka melihat kerangka kerja dari empat perspektif faktor yang memengaruhi motivasi pelajar L2 dan memisahkannya menjadi dua kategori, yakni faktor internal dan eksternal. Dalam kerangka ini, guru dipandang sebagai bagian dari faktor eksternal dalam kategori orang lain yang signifikan, dan interaksi dengan guru, termasuk pengalaman belajar, umpan balik, penghargaan, pujian dan hukuman juga dipandang sebagai faktor yang relevan yang dapat memengaruhi motivasi peserta didik L2. Root (2010) dalam penelitiannya menemukan bahwa "the number of comments in the diary, compared even to the number of learning strategies mentioned, also indicates the important role motivation plays in language learning". Komentar mahasiswa mengindikasikan bahwa strategi belajar yang digunakan oleh guru menjadi faktor penting yang memengaruhi motivasi belajar mahasiswa.

\section{Wujud Prospek Belajar Mahasiswa Amerika di BIPA UM}

Saud (2010) mengemukakan bahwa tujuan atau prospek belajar dapat dibagi menjadi lima jenis, yaitu (1) mengadakan perubahan di dalam diri atau mengubah tingkah laku (2) mengubah kebiasaan buruk menjadi baik, (3) mengubah sikap negatif menjadi positif, tidak hormat menjadi hormat, benci menjadi sayang, dan sebagainya, (4) meningkatkan kecakapan atau keterampilan, dan (5) menambah pengetahuan berbagai bidang ilmu. MacIntyre, Noels dan Moore (2010) menyatakan bahwa "any perspective that one might take will simultaneously reveal some of the processes and some of the phenomena that are involved in second language learning, while concealing other processes and other phenomena". Perspektif mahasiswa terhadap tujuan belajarnya kadang akan berubah seiring dengan proses pembelajaran dan fenomena yang mungkin dapat terjadi selama proses pembelajaran berlangsung. Perubahan-perubahan ini dapat menjadi masalah baru untuk dilakukan penelitian lanjutan.

Dari hasil penelitian ditemukan bahwa terdapat wujud prospek belajar yang sesuai dengan pendapat Saud. Data temuan ini didapatkan dari hasil wawancara terhadap beberapa sampel mahasiswa Amerika. Berikut ini adalah temuan-temuan dari penelitian mengenai wujud prospek belajar mahasiswa yang tercermin dalam jawaban hasil wawancara (Tabel 7).

\section{Tabel 7. Wujud Prospek Belajar Mahasiswa Amerika di BIPA UM}

\begin{tabular}{cl}
\hline No & \multicolumn{1}{c}{ Prospek Belajar } \\
\hline 1 & $\begin{array}{l}\text { Perubahan Tingkah } \\
\text { Laku/sikap }\end{array}$
\end{tabular}

2 Mengubah kebiasaan buruk menjadi baik
Kutipan

1) Acclimating to the distinctly different cultural norms and practices of Indonesia will be a challenge

2) Relationships I build in the group-based environment will give me the confidence I need to use the language to the best of my ability, on the other hand, I appreciate the more personal challenge of taking these skills outside of the classroom.

3) I intend to make a pact with my CLS peers during our orientation so that we agree to speak solely Indonesian unless it is necessary not to do so. My second concern involves my CLS peers. Because I am delighted about interacting with people from other cultures, I can picture myself not giving my fellow Americans enough attention.

4) I am confident that I will thrive in the program's intense academic environment.

5) I am glad the CLS program drives students to attend cultural events outside their discipline.

6) I expect the primary challenge for me to lay not in the country, or the language, or the dynamic of a closely-quartered group, but rather in the potential linguistic and developmental diversity of said group.

1) I hope to find community in the small intensive group that CLS has to offer, and to spend more time with my host family and see how their family dynamic may or may not differ from mine-and find comfort in that

2) I do expect to initially be shy to reach out to the greater community beyond the cohort and host family.

3) I've managed to tackle all the challenges of being abroad, while remaining motivated, energized and most of all, immersed.

4) Immersing myself in Bahasa Indonesian while adjusting to such a different environment and getting to know my CLS peers will pose challenges to a very verbal person like me, especially at the start.

3 Mengubah sikap dari negatif menjadi positif

1) I am excited by the new, and I am eager to embrace what might make me uncomfortable and learn from the experience.

2) I try my best to always find something positive to take away from difficult situations by always attempting to make friends or learn something valuable, even if I am required to do something I don't want to do.

3) My plan is to fully embrace any discomforts I face, and hopefully build and reflect on them on my path of personal growth

$4 \quad$ Meningkatkan keterampilan
1) My newest challenge will be to build on that newly made Indonesian base and strengthen the distinction in my mind between Malay and Indonesian.

2) I will choose to focus on each challenge, those that are social, academic and personal, as a learning experience

3) I love "building new relationships" and creating bonds with the people around me.

4) My goal is to become more and more proficient, learning local dialect and better understanding Indonesia from a cultural context.

5) I love people and learning about the perspectives of others, and I definitely love talking, but I need a certain amount of time alone in order to recharge my batteries, so to speak. 
Tabel 7. Wujud Prospek Belajar Mahasiswa Amerika di BIPA UM (Lanjutan)

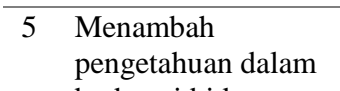
berbagai bidang
1) Adapting to a new environment, getting to know my host family, and becoming involved in opportunities outside of my program.

2) I hope to utilize this language study to carry out my Fulbright research project, which necessitates the ability to interview native Indonesian speakers.

3) I want to challenge myself and learn about whatmakes the culture what it is, rather than just view it from the surface. I know that I have to reflect on my experiences and debrief so I can truly understand what is happening around me. I do this by talking with others and by journaling.

4) I would approach with great enthusiasm, knowing that I would be able to learn so much about Javanese culture in this way.

5) I will face through the CLS program is attempting to pack in all of the connections and language growth that I expect to make in a much shorter program.

6) I welcome this challenge as an opportunity to practice interacting with people from many cultures

7) I will be more prepared to take on future academic and career demands.

8) The essence of overcoming cultural fatigue lies in careful time management, while of course realizing that surprises and unexpected events often come in the way, and realization of the unique and valuable opportunities provided by immersion.

9) I am confident that such challenges would be valuable learning and growth opportunities.

10) I will be intentional about journaling notes about my struggles and triumphs throughout the experience.

\section{Korelasi Motivasi dan Prospek terhadap Hasil Belajar Mahasiswa Amerika di BIPA UM}

Berdasarkan tabel 5 dan tentang wujud motivasi internal dalam kutipan-kutipan jurnal mahasiswa Amerika di BIPA UM dapat diketahui bahwa sikap menjadi indikator yang cukup memengaruhi motivasi. Terdapat enam kutipan mahasiswa yang menunjukkan bahwa sikap dapat menurunkan motivasi belajar mahasiwa, sedangkan pada indikator-indikator lain hanya terdapat 2-3 kutipan saja. Hanifiah dan Suhana (2009) menyatakan bahwa motivasi adalah daya pendorong (driving force), kekuatan (power), dan alat pembangun keinginan yang kuat secara internal untuk kreatif, aktif, inovatif, efektif dan menyenangkan dalam merubah perilaku dalam aspek afektif, kognitif, maupun psikomotor. Motivasi internal diharapkan dapat menjadi alat dan pendorong terjadinya perilaku yang positif terhadap prestasi, pencapaian tujuan pembelajaran, dan proses pembelajaran yang lebih bermakna. Pendapat lain oleh Purwanto (2000) yang menyatakan bahwa motivasi merupakan respons dan usaha yang ada dalam diri seseorang untuk mendorongnya melakukan sesuatu atau bekerja dengan harapan tujuan yang diinginkan akan tercapai dengan baik. Sadighi \& Zarafshan (2016) menyatakan bahwa "students finding some ways to communicate with the speakers of the target language; therefore, they build up social strategies more than other strategies". Mahasiswa akan lebih nyaman dan termotivasi untuk belajar dengan menggunakan startegi bersosialisasi. Mahasiswa yang cepat bersosialisasi akan cepat pula akrab dengan bahasa targetnya sehingga belajar akan lebih mudah dan termotivasi secara simultan. Berdasarkan pendapat tersebut dapat disimpulkan bahwa motivasi internal seperti sikap dapat menjadi daya dorong, kekuatan, alat pembangun keinginan dan respon/ usaha dari mahasiswa untuk meraih tujuannya (prospek) yang diharapkan.

Berdasarkan tabel 6 tentang wujud motivasi eksternal dalam kutipan-kutipan jurnal mahasiswa Amerika di BIPA UM dapat diketahui bahwa indikator orang yang berarti/ penting (10 kutipan), sifat dari interaksi dengan orang yang berarti (7 kutipan) dan lingkungan belajar (5 kutipan) menjadi indikator yang cukup memengaruhi motivasi. Indikator konteks yag lebih luas hanya memiliki tiga kutipan saja. Widoyoko (2012) menyatakan bahwa motivasi merupakan kondisi yang muncul yang disebabakan oleh kejadian, interaksi, dan motif yang mendorong untuk melakukan perubahan atau tindakan nyata terhadap hal yang dihadapi. Pendapat lain oleh Martinis (2010) menyatakan bahwa motivasi merupakan daya penggerak terhapat seseorang untuk melakukan kegiatan belajar, menambah pengalaman, menambah keterampilan dan meningkatkan prestasi. Faktor eksternal seperti bahan ajar juga cukup penting untuk dipertimbangkan demi tercapainya tujuan belajar. Ramadhani, Widodo, \& Harsiati (2016) menyatakan bahwa latihan yang kurang bervariasi dapat menyebabkan mahasiswa merasa bosan dan akhirnya hanya dapat menguasai sebagian materi dan latihan yang diberikan oleh guru. Latihan yang bervariasi dimaksudkan agar mahasiswa dapat mengusai empat keterampilan bahasa dengan lebih maksimal. Matsumoto (2009) dalam penelitiannya menemukan bahwa "teacher influences his/her students' motivation. In addition, the study also indicates that learners' levels of proficiency may be an important factor which can determine the effectiveness of teaching strategies as a motivator for learners". Pengajar dan strategi yang digunakan dapat memengaruhi motivasi belajar mahasiswa untuk meraih hasil belajar yang maksimal. Gunawan, Hariyono \& Sapto (2017) menyatakan bahwa kebudayaan yang ada di sekitar lingkungan belajar siswa dapat dijadikan sebagai topik atau sumber belajar yang lebih kontekstual. Natalia (2018) menyatakan bahwa kita harus lebih berhati-hati dalam berkomunikasi dengan orang dari latar belakang budaya yang berbeda karena budaya dan komunikasi adalah dua hal yang saling terhubung sehingga kesalahpahaman sangat mungkin terjadi. Neuzil (2016) menyatakan bahawa "Culture is communication and communication is culture”. Komunikasi dan budaya adalah dua hal yang tidak dapat dipisahkan sehingga mahasiswa akan cenderung berkomunikasi sesuai dengan budaya yang dimilikinya. Berdasarkan pendapat tersebut dapat disimpulkan bahwa motivasi eksternal dapat menjadi sebuah kondisi yang muncul dari kejadian, interaksi, motif dan daya penggerak mahasiswa untuk melakukan perubahan sehingga pada akhirnya akan meraih tujuan/ prospek yang diharapkan. 
Motivasi yang dibagi menjadi faktor internal dan eksternal dapat diskala dan difrekuensikan untuk mengetahui korelasinya terhadap hasil belajar. Hasil dari analisis data motivasi belajar menunjukkan bahwa terdapat korelasi yang positif dan signifikan antara motivasi mahasiswa Amerika terhadap hasil belajar. Hal ini juga didukung oleh hasil kutipan jurnal mahasiswa menunjukkan bahwa setiap indikator motivasi internal dan eksternal memiliki deskrisi yang korelatif antara motivasi dengan hasil belajar mahasiswa Amerika di BIPA UM.

Berdasarkan tabel 7 tentang wujud prospek belajar mahasiswa Amerika di BIPA UM dapat diketahui bahwa prospek mahasiswa untuk mengadakan perubahan di dalam diri atau mengubah tingkah laku (6 mahasiswa), mengubah kebiasaan buruk menjadi baik (4 mahasiswa), mengubah sikap negatif menjadi positif ( 3 mahasiswa), meningkatkan kecakapan atau keterampilan (6 mahasiswa) dan menambah pengetahuan berbagai bidang ilmu (10 mahasiswa). Prospek belajar mahasiswa yang dibagi menjadi 5 jenis teresut pada akhirnya menunjukkan bahwa hasil wawancara berbanding lurus dengan klasifikasi tersebut. Prospek belajar tentunya dapat dicapai dengan motivasi belajar yang memiliki korelasi positif dan signifikan terhadap hasil belajar. Dengan demikian, hasil analisis data yang menunjukkan bahwa terdapat korelasi yang positif dan signifikan antara motivasi terhadap hasil belajar sudah cukup membuktikan bahwa prospek belajar mahasiswa Amerika di program BIPA UM telah tercapai. Namun, ada beberapa karakter prospek yang belum dapat dikatakan tercapai seperti prospek dengan jangka panjang dan perubahan sikap yang tidak dapat diukur. Prospek juga memiliki kecenderungan untuk berubah-ubah seiring berjalannya proses pembelajaran. Sehingga korelasi antara motivasi dan prospek terhadap hasil belajar sebenarnya dapat diuji berulang kali dengan penyesuaian perubahan prospek yang terjadi.

\section{SIMPULAN}

Berdasarkan hasil analisis data motivasi belajar dan hasil belajar mahasiswa dapat ditarik kesimpulan terdapat korelasi yang positif dan signifikan antara motivasi mahasiswa Amerika terhadap hasil belajar bahasa Indonesia. Hal ini berarti bahwa hipotesis $\left(\mathrm{H}_{1}\right)$. Penyimpulan ini berdasar pada pengujian rumus nilai r-hitung > r-tabel $(0,796>0,576)$. Pengambilan kesimpulan ini juga berdasar pada hasil uji normalitas dan uji linieritas yang menunjukkan bahwa data berdistribusi normal dan ada hubungan linier secara signifikan antara variabel motivasi belajar dengan variabel prestasi belajar.

Wujud motivasi belajar mahasiswa dapat dibagi menjadi dua faktor, yaitu internal dan eksternal yang masing-masing memiliki indikator yang dapat diskala dan difrekuensikan untuk mengetahui apakah indikator tersebut berpengaruh atau tidak terhadap hasil belajar. Hasil kutipan jurnal mahasiswa menunjukkan bahwa teori dari Williams dan Burden's tentang wujud motivasi internal dan eksternal adalah benar. Setiap indikator motivasi internal dan motivasi eksternal memiliki deskrisi yang jelas dan tercermin dalam kutipan dari jurnal mahasiswa. Motivasi internal dapat dijawabarkan ke dalam 8 faktor, yaitu (1) ketertarikan intrinsik pada kegiatan, (2) nilai yang dirasakan dalam kegiatan, (3) rasa pengendalian, (4) penguasaan, (5) konsep diri, (6) sikap, (7) keadaan afektif lain dan (8) perkembangan usia dan jenis kelamin. Motivasi eksternal dapat dijawabarkan ke dalam 4 faktor, yaitu (1) orang yang berarti/penting, (2) sifat dari interaksi dengan orang yang berarti, (3) lingkungan belajar, dan (4) konteks yang lebih luas.

Wujud prospek belajar mahasiswa Amerika dapat dibagi menjadi lima jenis, yaitu perubahan tingkah laku/sikap, mengubah kebiasaan buruk menjadi baik, mengubah sikap dari negatif menjadi positif, meningkatkan keterampilan, dan menambah pengetahuan dalam berbagai bidang. Hasil kutipan wawancara dengan mahasiswa Amerika menunjukkan bahwa prospek mahasiswa dapat didistribusikan ke dalam lima jenis prospek belajar, yaitu (1) perubahan tingkah laku/sikap, (2) mengubah kebiasaan buruk menjadi baik, (3) mengubah sikap dari negatif menjadi positif, (4) meningkatkan keterampilan, dan (5) menambah pengetahuan dalam berbagai bidang.

Berkaitan dengan hasil penelitian, maka ada beberapa saran yang dapat penulis sampaikan, yaitu (1) peneliti selanjutnya dapat mengembangkan variabel lain yang diduga berkorelasi terhadap hasil belajar mahasiswa Amerika dalam belajar bahasa Indonesia guna melengkapi pemahaman atas faktor-faktor yang berkorelasi terhadap hasil belajar bahasa Indonesia, (2) peneliti selanjutnya harus lebih mempertimbangkan lama waktu penelitian dan keterbatasan sumber data karena kuesioner, wawancara, data diri, hasil belajar, dan prospek adalah hal yang masuk dalam kategori "privasi” bagi mahasiswa amerika, dan (3) prospek belajar memiliki kecenderungan untuk dapat berubah sewaktu-waktu seiring dengan proses pembelajaran berlangsung. Peneliti merasa ini dapat menjadi masalah baru untuk dapat dilakukan penelitian lanjutan terhadap masalah tersebut.

\section{DAFTAR RUJUKAN}

Agustina, R., Andayani., \& Wardani, N. E. (2013). Implementasi Pembelajaran Bahasa Indonesia bagi Penutur Asing di UPT P2B Universitas Sebelas Maret Surakarta. Jurnal Pendidikan Bahasa dan Sastra, 1(2), 140_-154.

Azizah, Widodo, Hs., \& Lestari, I. (2015). Pembelajaran Bahasa Indonesia bagi Penutur Asing (BIPA) Program CLS (Critical Language Scholarship) di Fakultas Sastra Universitas Negeri Malang Tahun 2012. Jurnal Pendidikan Bahasa dan Sastra Indonesia , 4(2), 1-13.

Chaer, A. (2009). Psikolinguistik: Kajian Teoritik. Cetakan Kedua. Jakarta: PT Rineka Cipta.

Dimyati \& Mudjiono. (2010). Belajar dan Pembelajaran. Jakarta: Rineka Cipta.

Ellis, R. (2013). Second Language Acquisition. Oxford University Press. 
Gunawan, A., Hariyono., \& Sapto, A. (2017). Perbedaan Hasil Belajar Ilmu Pengetahuan Sosial dengan Pendekatan Kontekstual Berbasis Budaya Lokal di Madura. Jurnal Pendidikan: Teori, Penelitian, dan Pengembangan, 2(6), 867873.

Jamal, S. (2017). Pengaruh Motivasi Belajar terhadap Prestasi Belajar IPS Siswa Kelas VIII SMP N 2 Srumbung. Social Studies, 6(4), 469-479.

Jamil, H., \& Azra, F. I. (2014). Pengaruh Lingkungan Keluarga dan Motivasi Belajar Siswa terhadap Hasil Belajar Akuntansi ECONOMICA: Journal of Economic and Economic Education, 2(2), 85-98.

Macintyre, P. D., Noels, K. a, \& Moore, B. (2010). Perspectives on Motivation in Second Language Acquisition : Lessons from the Ryoanji Garden. Selected Proceedings of the 2008 Second Language. Research Forum: Exploring SLA Perspectives, Positions, and Practices. Cascadilla Proceedings Project, 1-9.

Martinis, Y. (2010). Profesionalisasi Guru \& Implementasi KTSP. Jakarta: Gaung Persada Press.

Matsumoto, M. (2009). Second Language Learners' Motivation and Their Perceptions of Teachers' Motivation. Humanities \& Social. Sciences Papers, 1-16.

Nanang, H., \& Suhana. (2009). Konsep Strategi Pembelajaran. Bandung: PT Refika Aditama.

Nari, N. (2011). Kemampuan Pemahaman Konsep Matematika dengan menerapkan Pendekatan Pembelajaran Kontekstual melalui Model Pembelajaran Kooperatif Think-Pair-Share Berempat dan Kemunculan Komponen Pembelajaran Kontekstual. Jurnal Ta'dib, 14(1), 26-35.

Natalia, E. C. (2018). Pemilihan Penggunaan Bahasa dalam Interaksi sebagai Bentuk Adaptasi Antarbudaya di Indonesia. Jurnal Komunikasi Indonesia, 4(2), 73-86. https://doi.org/10.7454/jki.v4i2.8883.

Neuzil, P. (2016). Communication between Cultures. Nucleic Acids Research, 34(11), e77-e77.

Novalinda, E., Kantun, S., \& Widodo, J. (2017). Pengaruh Motivasi Belajar terhadap Hasil Belajar Mata Pelajaran Akuntansi Siswa Kelas X Jurusan Akuntansi Semester Ganjil SMK PGRI 5 JemberTahun Pelajaran 2016/2017. Jurnal Pendidikan Ekonomi, 1-15.

Prihatin, M. S. (2017). Pengaruh Fasilitas Belajar, Gaya Belajar dan Minat Belajar terhadap Hasil Belajar Mata Pelajaran Ekonomi Siswa Kelas XI IS SMA Negeri 1 Seyegan. Jurnal Pendidikan dan Ekonomi, 6(5), 443-452.

Purwanto, N. (2000). Psikologi Pendidikan. Bandung: PT. Remaja Rosda Karya.

Puspitasari, E., Setyosari, P., \& Amirudin, A. (2016). Peningkatan Motivasi dan Hasil Belajar melalui Think Pair Share (TPS) di Sekolah Dasar. Jurnal Pendidikan: Teori, Penelitian, dan Pengembangan, 1(7), 1432-1436.

Rahman, M. F. (2015). Pengaruh Dukungan Orangtua dan Fasilitas Belajar di Sekolah terhadap Prestasi Belajar Ekonomi Melalui Motivasi Belajar Siswa Kelas VIII SMP Negeri 2 Ungaran. Prosiding Seminar Pendidikan Ekonomi dan Bisnis, $1(1)$.

Ramadhani, R., Widodo, Hs., \& Harsiati, T. (2016). Pengembangan Bahan Ajar Keterampilan Berbicara Bahasa Indonesia bagi Penutur Asing Tingkat Pemula. Jurnal Pendidikan: Teori, Penelitian, dan Pengembangan, 1(3), 326-337.

Ramliyana, R. (2016). Membangkitkan Motivasi Belajar Bahasa Indonesia bagi Penutur Asing (BIPA) Melalui Media Komik. Dialektika: Jurnal Bahasa, Sastra, dan Pendidikan Bahasa dan Sastra Indonesia, 3(1), 1-19.

Root, E. (2000). Motivation and Learning Strategies in a Foreign Language Setting: A Look at a Learner of Korean. Department of English as a Second Language University of Minnesota.

Sardiman, M. (2007). Interaksi dan Motivasi Belajar Mengajar. Jakarta: Grafindo.

Saud, S. (2010). Pengembangan Profesi Guru. Bandung: Alfabeta.

Siroj, M. (2015). Pengembangan Model Integratif Bahan Ajar Bahasa Indonesia Ranah Sosial Budaya Berbasis ICT bagi Penutur Asing Tingkat Menengah. Jurnal Pendidikan Bahasa dan Sastra Indonesia, 4(2), 1-13.

Slameto. (2010). Belajar dan Fakta-fakta yang Memengaruhinya. Jakarta: Rineka Cipta.

Soemanto, W. (1990). Psikologi Pendidikan Landasan Kerja Pemimpin Pendidikan. Jakarta: Rineka Cipta.

Sudjana, N. (2009). Penilaian Hasil Proses Belajar Mengajar. Bandung: PT Remaja Rosdakarya.

Sulaeman, A. (2019). Motivasi Pemelajaran Bahasa Indonesia bagi Penutur Asing (BIPA) Mahasiswa Peminatan BIPA Prodi PBSI FKIP Universitas Muhammadiyah Tangerang. Artikel Simposium Nasional Multidisiplin (SinaMu). 1 - 9.

Widoyoko, Eko. (2012). Evaluasi Program Pembelajaran.Yogyakarta: Pustaka Pelajar.

Williams, M., \& Burden, R. (1997). Psychology for Language Teachers. Cambridge: Cambridge University Press.

Zarafshan., \& Sadighi, F. (2016). Effects of Attitude and Motivation on the Use of Strategies by Iranian EFL University Students. Journal of Social Sciences \& Humanities of Shiraz University, 23(1). 